\title{
Comparison of zona cutting and zona drilling as techniques for assisted fertilization in the mouse
}

\author{
H. T. Depypere, K. J. McLaughlin*, R. F. Seamark*, G. M. Warnes and \\ C. D. Matthews \\ Reproductive Medicine Unit, University of Adelaide, The Queen Elizabeth Hospital, Woodville, \\ South Australia 5011, Australia and ${ }^{*}$ Department of Obstetrics and Gynaecology, University of \\ Adelaide, GPO Box 498, Adelaide, South Australia 5001, Australia
}

\begin{abstract}
Summary. Zona cutting and zona drilling of the mouse oocyte significantly increased the fertilization rate $(3 \cdot 8-90 \%)$ at low sperm concentrations $(<200000 / \mathrm{ml})$ compared with zona-intact controls $(0-45 \%)$. More oocytes were fertilized after zona drilling. Zona cutting was associated with a low loss of oocytes $(<1 \%)$, no increase in polyspermy and normal development in vitro and in vivo after fertilization. There was a $4 \%$ oocyte loss rate after zona drilling, mostly due to extrusion of the oocyte from the zona during the procedure. Hatching of blastocysts occurred about $12 \mathrm{~h}$ earlier for zonadrilled than for zona-cut and zona-intact control oocytes. Zona drilling was associated with a higher, but not statistically significant, rate of polyspermy at all sperm concentrations tested.

The proportion of zygotes developing to the blastocyst stage was not different between the techniques (zona cut, 77\%; zona drilled, 66\%; control, $71 \%$ ). Similarly, no difference was found in the percentage of embryos implanting after blastocyst transfer to the uterine horns of pseudopregnant female mice (zona cut, $67 \%$; zona drilled, $68 \%$; control, $77 \%$ ).

Transmission electron microscopy demonstrated the induced defects in the zona with no damage to the oocyte or oolemma. Parthenogenetic activation was not seen after either of the micromanipulative techniques. Both techniques have promise for application to the human.
\end{abstract}

Keywords: in-vitro fertilization; oligospermia; zona drilling; zona cutting; polyspermy

\section{Introduction}

In mammalian reproduction the waste of spermatozoa is substantial. While many millions are deposited at coitus only a few are believed to gain access to the oocyte (Braden \& Austin, 1954). This presumably affords an explanation as to why oligospermic men are subfertile or sterile in natural circumstances.

Intrauterine insemination (Kerin et al., 1984), in-vitro fertilization (Yovich \& Stanger, 1984; Cohen et al., 1985; Diamond et al., 1985) and gamete intra-Fallopian transfer (GIFT) (Corson et al., 1986) have been explored as approaches to correct infertility due to oligospermia but the results are generally disappointing and below those obtained using normal semen. The introduction of a safe technique to reduce the numbers of spermatozoa required for normal fertilization and

*Department of Obstetrics and Gynaecology, University of Adelaide, GPO Box 498, Adelaide, South Australia 5001, Australia. 
embryonic development would constitute a major advance and would allow in-vitro fertilization to be successfully applied to many additional infertile couples.

Several techniques of assisted fertilization have been described. Direct microinjection of spermatozoa or sperm nuclei into the cytoplasm of mouse oocytes (Uehara \& Yanagimachi, 1976; Thadani, 1982; Markert, 1983) was associated with an unacceptably high rate of damage to the oocytes. Subzonal injection of spermatozoa has also been reported (Metka et al., 1985; Barg et al., 1986; Lassalle et al., 1987). The disadvantages associated with this technique include the artificial selection of an individual spermatozoon, the time-consuming skills required for the technique, the low fertilization rate and questions relating to the karyotypic normality of the resulting embryos. Complete removal of the zona pellucida permits a marked reduction of the sperm/oocyte ratio (Thadani, 1982), but is associated with high rates of polyspermic fertilization. More recently, a micromanipulative technique of weakening of the zona pellucida has been developed in which discrete regions of the zona are dissolved with acidified Tyrode's medium applied through a microneedle. This approach was claimed to show a substantial improvement in the sperm/oocyte ratio without increasing the incidence of polyspermia (Gordon \& Talanski, 1986). The mechanical disruption of the zona pellucida by cutting with a microneedle has been utilized for nuclear manipulation (Tsunoda et al., 1986) but has not been studied in relation to assisted fertilization.

This study reports the results after zona cutting and zona drilling with respect to performance of the techniques, damage to the oocyte, fertilization in vitro, polyspermia and development in vivo.

\section{Materials and Methods}

Oocytes and sperm collection. For each replicate experiment 4-6 (C57BL/6 $\times$ CBA) F1 hybrid mice were superovulated and the ova collected as described by Quinn \& Whittingham (1982). The cumulus masses were collected into Hepes-buffered human tubal fluid (HTF) medium (Quinn et al., 1985) containing $5 \mathrm{mg}$ bovine serum albumin/ml (BSA; fraction V; Sigma Chemical Company, St Louis, MO, U.S.A.) and 300 i.u. hyaluronidase $/ \mathrm{ml}$ (bovine testis type IS H 3506; Sigma). After 10 min the cumulus-free oocytes were washed in Hepes-HTF medium and transferred to drops of the same medium under oil (Heavy Paraffin; BDH, Poole, Dorset, U.K.).

The cumulus-free oocytes were divided into three groups each of about 50 oocytes. One group was submitted to zona cutting, a second group underwent zona drilling and a third group served as zona-intact controls. Oocytes in all 3 groups were transferred at the same time to $0.5 \mathrm{ml}$ fertilization droplets with the designated number of epididymal spermatozoa collected approximately $2 \mathrm{~h}$ earlier from males of the same hybrid line (Stanger \& Quinn, 1982). Fertilization and polyspermy were assessed at sperm concentrations ranging from $2 \times 10^{6}$ to $5 \times 10^{3} / \mathrm{ml}$.

The fertilization dishes and the microdrops for further culture contained bicarbonate-buffered HTF medium and were prepared the day before use and incubated at $37^{\circ} \mathrm{C}$ in an humidified desiccator through which a constant stream of humidified $5 \% \mathrm{O}_{2}+5 \% \mathrm{CO}_{2}+90 \% \mathrm{~N}_{2}$ was passed. The desiccator was housed in a $5 \% \mathrm{CO}_{2}$ in air incubator.

Micromanipulation. Micropipettes were prepared on a De Fonbrune microforge. The cutting needles were pulled on a Brown Flaming P77 B pipette puller. Oocytes were micromanipulated in Hepes-HTF medium under oil using a Nikon Diaphot inverted microscope with differential interference-contrast optics and Narishige micromanipulators.

The drilling procedure was carried out as described by Gordon \& Talanski (1986) using a $10 \mu \mathrm{m}$ diameter micropipette. Zona cutting was performed as described by Tsunoda et al. (1986). After micromanipulation, oocytes were washed in bicarbonate-buffered HTF medium and transferred into the sperm suspension dishes for fertilization. After $5 \mathrm{~h}$ the oocytes were washed and transferred to microdrops of Hepes-HTF medium under oil. All incubations were under a gas phase of $5 \% \mathrm{CO}_{2}+5 \% \mathrm{O}_{2}+90 \% \mathrm{~N}_{2}$ at $37^{\circ} \mathrm{C}$. The oocytes were assessed for fertilization $6 \mathrm{~h}$ after removal from the sperm suspension using a Nikon inverted microscope with differential interference-contrast optics. The criteria for fertilization included the presence of two polar bodies and at least two pronuclei.

In-vitro and in-vivo development. After assessment for fertilization the embryos were transferred back to microdrops of bicarbonate-buffered HTF medium for further culture. The fertilized oocytes were assessed every morning and evening for their developmental stage. Blastocysts were subsequently transferred to the uterine horns of pseudopregnant C57BL $\times$ CBA female mice at Day 2.5 after mating with a vasectomized male. The mice were killed on Day 15 to assess the numbers of implantation sites and embryonic development.

For detailed morphological studies, oocytes were fixed in glutaraldehyde, embedded in agar and stained with uranyl acetate/lead citrate.

Statistics. The effects of sperm concentration on fertilization rate were examined by fitting a response curve to the results for each group, using the BMDP program LR (BMDP Statistical Software, Los Angeles, CA 90025, U.S.A.). 
A log linear analysis was used to compare the three groups. In-vivo and in-vitro development results were analysed by using $\chi^{2}$ analysis.

\section{Results}

\section{Sperm concentration effects}

The rates of fertilization and the incidence of polyspermia in the three groups at different sperm concentrations are shown in Table 1 . The rate of fertilization was clearly dependent on the sperm concentrations in a dose-dependent manner. Overall, both methods of micromanipulation resulted in significantly higher fertilization rates in comparison with zona-intact controls, while the fertilization rate was significantly higher after zona drilling than after zona cutting. With $2 \times 10^{6}$ spermatozoa/ml no difference was evident in the rate of fertilization in the three different treatment groups, indicating that the micromanipulation did not impair fertilization at this optimal sperm concentration. When the sperm concentration was decreased to $200000 / \mathrm{ml}$ ( $\sim 2000$ spermatozoa/ oocyte), the fertilization rate was substantially reduced in the controls compared with zona-drilled and zona-cut oocytes. Further decrease in the sperm concentration led to reductions in fertilization rate in all 3 groups (Table 1).

Table 1. The rate of fertilization and polyspermy of mouse oocytes after zona cutting and zona drilling compared with unoperated zona-intact controls at various sperm concentrations

\begin{tabular}{|c|c|c|c|c|c|c|c|c|c|}
\hline \multirow[b]{2}{*}{$\begin{array}{l}\text { Sperm conc. } \\
\left(\times 10^{-3} / \mathrm{ml}\right)\end{array}$} & \multicolumn{3}{|c|}{ Oocytes treated } & \multicolumn{3}{|c|}{ Fertilized oocytes $(\%)^{*}$} & \multicolumn{3}{|c|}{ Polyspermic oocytes $(\%)$} \\
\hline & Control & $\begin{array}{c}\text { Zona } \\
\text { drilled }\end{array}$ & $\begin{array}{c}\text { Zona } \\
\text { cut }\end{array}$ & Control & $\begin{array}{l}\text { Zona } \\
\text { drilled }\end{array}$ & $\begin{array}{c}\text { Zona } \\
\text { cut }\end{array}$ & Control & $\begin{array}{c}\text { Zona } \\
\text { drilled }\end{array}$ & $\begin{array}{c}\text { Zona } \\
\text { cut }\end{array}$ \\
\hline 2000 & 130 & 140 & 162 & $116(89)$ & $134(96)$ & $153(94)$ & $4(3 \cdot 4)$ & $9(6 \cdot 7)$ & $9(5 \cdot 9)$ \\
\hline 200 & 214 & 233 & 207 & $97^{2}(45)$ & $210^{\mathrm{b}}(90)$ & $157^{\mathrm{c}}(76)$ & 0 & $7(3 \cdot 3)$ & $2(1 \cdot 3)$ \\
\hline 20 & 208 & 190 & 165 & $11^{\mathrm{a}}(5 \cdot 3)$ & $139^{\mathrm{b}}(73)$ & $46^{c}(28)$ & 0 & $10(7 \cdot 2)$ & $1(2 \cdot 2)$ \\
\hline 10 & 155 & 148 & 147 & 0 & $32^{\mathrm{a}}(22)$ & $9^{b}(6)$ & 0 & 0 & 0 \\
\hline 5 & 152 & 146 & 156 & 0 & $7^{a}(4 \cdot 8)$ & $6^{a}(3 \cdot 8)$ & 0 & 0 & 0 \\
\hline
\end{tabular}

*Includes polyspermy.

Values not sharing a common superscript in the same row are significantly different $(P<0.05)$.

An estimate of the sperm concentration required to achieve a $50 \%$ fertilization rate in the treatment groups was derived from a log-linear plot of the data presented in Table 1 supplemented with observations made in 4 other experimental groups.

The additional groups were zona-drilled oocytes exposed to 15000 spermatozoa/ml (148 oocytes, 83 fertilized, 4 polyspermic), zona-cut oocytes exposed to 50000 spermatozoa $/ \mathrm{ml}(151$ oocytes, 93 fertilized, 2 polyspermic), control oocytes exposed to 50000 spermatozoa/ml (150 oocytes, 65 fertilized, none polyspermic) and control oocytes exposed to 500000 spermatozoa $/ \mathrm{ml}$ (145 oocytes, 90 fertilized, 2 polyspermic). The sperm concentrations required to achieve a $50 \%$ fertilization rate calculated by this means, including polyspermic embryos, was $2.5 \times 10^{5}$ for controls, $4.6 \times 10^{4}$ for zona-cut oocytes and $1.4 \times 10^{4}$ spermatozoa $/ \mathrm{ml}$ for zona-drilled oocytes.

\section{Polyspermy}

Polyspermy (Table 1) was observed in the zona-drilled oocytes at all sperm concentrations but the rate was not significantly different $(P>0.05)$ from that of the controls. Parthenogenetic activation was assessed by subjecting approximately 150 oocytes to zona drilling or zona cutting and transferring the oocytes to microdrops without spermatozoa. No pronuclear formation, second polar body extrusion or spontaneous cleavage was observed after micromanipulation. 


\section{Pipette size}

The effect of pipette size on fertilization of zona-drilled oocytes was evaluated by comparing pipettes of 10 or $20 \mu \mathrm{m}$ diameter at a sperm concentration of 20000 spermatozoa $/ \mathrm{ml}$. No difference in fertilization rate $(72 \%$ vs $70 \%)$ or polyspermy rate $(8 \%$ vs $6 \%)$ was observed with the use of $10 \mu \mathrm{m}$ and $20 \mu \mathrm{m}$ pipettes respectively.

\section{Morphological studies}

Transmission electron microscopy confirmed the nature of the lesion in the zona created by the drilling and cutting techniques (Figs 1 and 2). The zona-drilling procedure appeared to create a bigger defect in the zona pellucida compared to zona cutting for which the slit tended to close following removal of the microneedle because of the natural elasticity of the zona (see Fig. 2). Zona drilling also caused a thinning of the surrounding zona (Fig. 1).

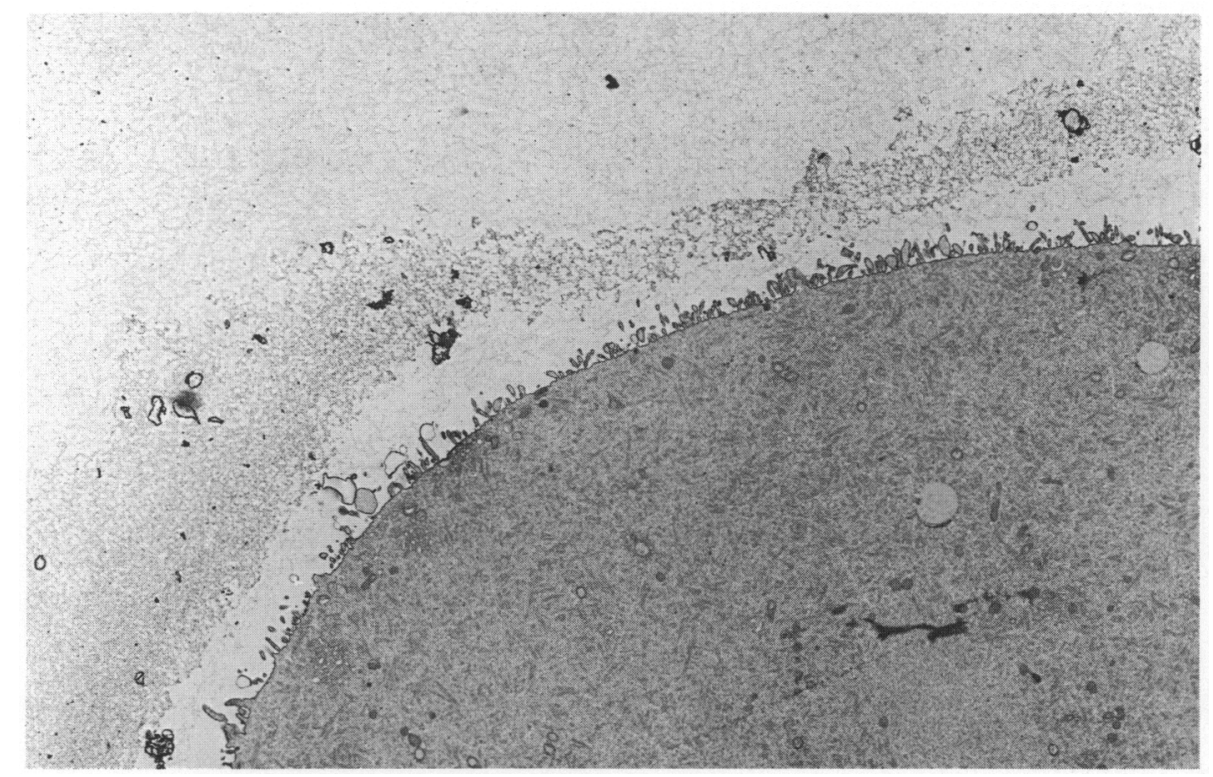

Fig. 1. Transmission electron photomicrograph of a zona-drilled oocyte $(\times 6100)$ showing thinning of the zona pellucida around the drilled region.

\section{Development in vitro}

Development to the blastocyst stage was not impaired after micromanipulation (Table 2). No differences were observed in the percentage of treated oocytes which formed blastocysts after fertilization. The zona-drilled blastocysts, however, hatched about $12 \mathrm{~h}$ earlier than did the zonacut or zona-intact controls. On the evening of Day 5 the embryos obtained after zona drilling had consistently hatched, while zona-cut and zona-intact controls were still hatching. Hatching was complete in the last two groups by the morning of Day 6. 


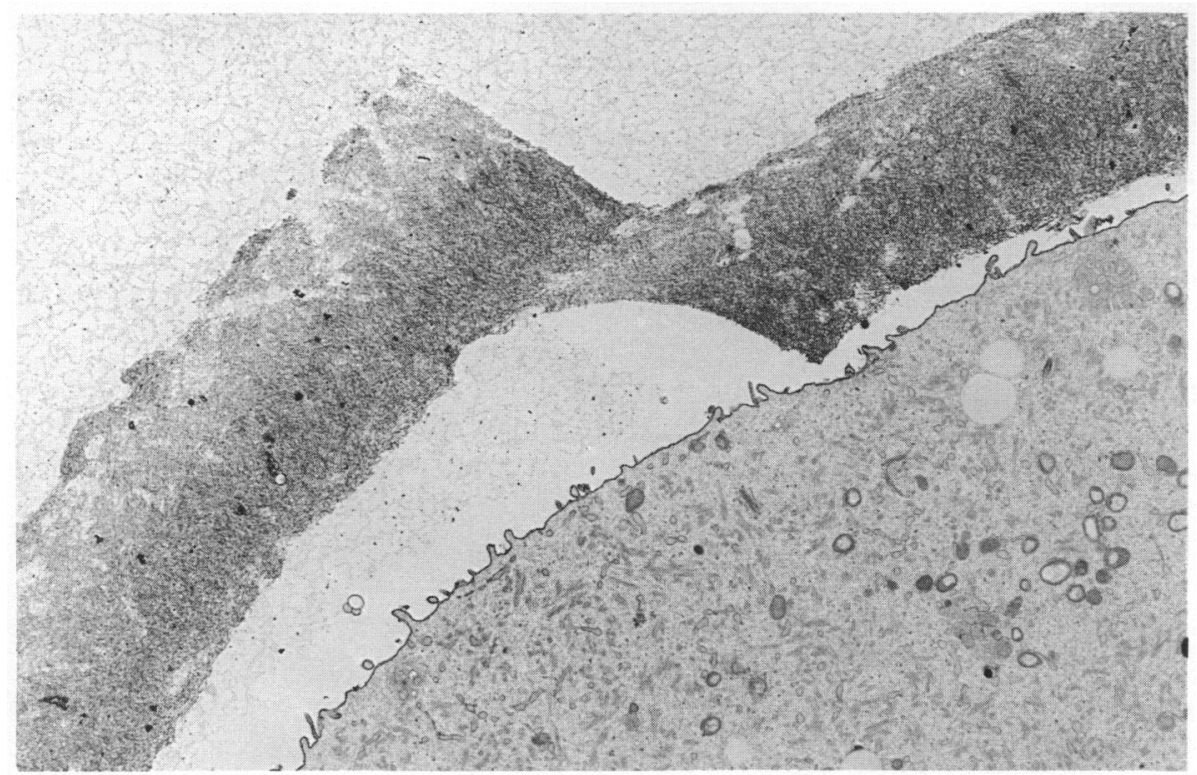

Fig. 2. Transmission electron photomicrograph of a zona-cut oocyte $(\times 7400)$ showing the cut in the zona.

Table 2. In-vitro development of micromanipulated mouse oocytes after fertilization

\begin{tabular}{lcc}
\hline Treatment & $\begin{array}{c}\text { Oocytes } \\
\text { fertilized }\end{array}$ & $\begin{array}{c}\text { Blastocysts } \\
(\%)\end{array}$ \\
\hline Controls & 150 & $107(71 \%)$ \\
Drilled & 201 & $132(66 \%)$ \\
Cut & 187 & $144(77 \%)$ \\
& & $\chi_{2}^{2}=6.09$ (NS) \\
\hline
\end{tabular}

\section{Development in vivo}

No differences were observed in the rates of implantation and fetal development after the replacement of embryos derived from micromanipulated oocytes when compared with control oocytes (Table 3).

\section{Discussion}

For reasons which are still not completely understood fertilization in vitro requires a much higher number of spermatozoa (Fraser \& Drury, 1975) than does fertilization in vivo for which only a few spermatozoa gain access to the oocyte to complete fertilization (Braden \& Austin, 1954). The high number of spermatozoa required appears to be a feature of culture conditions and not to the hypothetical possibility that only few spermatozoa amongst the high number present have fertilizing ability. Under conditions which facilitate fertilization in vitro with reduced numbers of spermatozoa per oocyte, most spermatozoa have been shown to have fertilizing ability since 
Table 3. In-vitro development of micromanipulated mouse embryos after uterine transfer to pseudopregnant mice

(Day $2 \cdot 5$ after mating)

\begin{tabular}{lccc}
\hline Treatment & $\begin{array}{c}\text { Blastocysts } \\
\text { transferred }\end{array}$ & $\begin{array}{c}\text { Implantation } \\
\text { sites }(\%)^{*}\end{array}$ & $\begin{array}{c}\text { Fetuses } \\
(\%) \dagger\end{array}$ \\
\hline Controls & 96 & $74(77)$ & $49(66)$ \\
Drilled & 117 & $79(68)$ & $45(57)$ \\
Cut & 100 & $67(67)$ & $43(64)$ \\
& & $\chi_{2}^{2}=3.1(\mathrm{NS})$ & $\chi_{2}^{2}=1.6(\mathrm{NS})$ \\
\hline
\end{tabular}

*Implantation sites per embryo transferred.

$\dagger$ Fetuses per implantation site.

randomly selected spermatozoa from a sperm suspension are able to fertilize zona-intact (Bavister, 1979) and zona-free oocytes (Thandani, 1982) in vitro. Removing the zona pellucida from mouse oocytes allows a substantial reduction of the sperm/egg ratio (approximately 5-10 spermatozoa/ oocyte) with a fertilization rate of about $70 \%$ (Thadani, 1982). However, removal of the zona is associated with a high incidence of polyspermy (Barros \& Yanagimachi, 1971; Fukuda \& Chang, 1978) and impairs tubal transport and implantation (Modlinski, 1970).

The micromanipulative techniques of zona drilling and zona cutting significantly improved the fertilization rate compared with zona-intact controls at suboptimal concentrations of spermatozoa. Both techniques are associated with low rates of oocyte loss $(<1 \%$ in the zona-cut group). The major proportion of the $4 \%$ loss rate after zona drilling was due to extrusion of the oocyte from the disrupted zona pellucida while still retained on the holding pipette at micromanipulation. Less than $0.5 \%$ was due to direct lysis of the oocyte.

The finding that zona-drilled embryos had a high fertilization rate and hatched about $12 \mathrm{~h}$ earlier than the controls or zona-cut embryos presumably reflects the more substantial impact of zona drilling. In zona-drilled oocytes polyspermy was evident at all sperm concentrations tested, but the rate was not statistically significantly different from that of control oocytes. There appeared to be no advantage in increasing the size of the pipette above $10 \mu \mathrm{m}$ in diameter as the $20 \mu \mathrm{m}$ pipettes tested had no discernible effect, either on the rate of fertilization at low sperm concentrations or the rate of polyspermy.

Previous work (Tsunoda \& McLaren, 1983) showed reduced implantation of micromanipulated embryos. However, in that study the zona pellucida showed additional damage associated with blastomere removal and the number of blastomeres was changed, which may account for the reduced rate of implantation. No significant reduction in the rate of embryo implantation was present in our study.

Parthenogenetic activation was not observed with either micromanipulative technique, again probably reflecting the minimal damage to the oocyte from these methods.

This study has shown that zona drilling and zona cutting techniques both improve fertilization rates at low sperm concentrations, and that both techniques are compatible with normal embryonic development and are relatively easy to perform. The results encourage the application of these techniques, particularly zona drilling, to human in-vitro fertilization for patients in whom suboptimal semen parameters result in reduced rates of fertilization.

We thank Dr P. Leppard (Department of Statistics, University of Adelaide), Mr John Carroll and Ms Dianna Payne (Reproductive Medicine Unit) for advice; the Electron Microscopy Unit of The Queen Elizabeth Hospital for preparing the photomicrographs; and Ms Gina Perrotta for typing the manuscript. 


\section{References}

Barg, P.E., Wahrman, M.Z., Talansky, B.E. \& Gordon, J.W. (1986) Capacitated, acrosome reacted but immotile sperm, when microinjected under the mouse zona pellucida, will not fertilize the oocyte. $J$. exp. Zool. 237, 365-374.

Barros, C. \& Yanagimachi, R. (1971) Induction of the zona reaction in golden hamster by cortical granule material. Nature, Lond. 233, 268-269.

Bavister, B.D. (1979) Fertilization of hamster eggs in vitro at sperm:egg ratios close to unity. J. exp. Zool. 210, 259-264.

Braden, A.W.H. \& Austin, C.R. (1954) The number of sperm about the eggs in mammals and its significance for normal fertilization. Aust. J. Biol. Sci. 7, 543-551.

Cohen, J., Edwards, R., Fehilly, C., Fishel, S., Hewitt, J., Purdy, J., Rowland, G., Steptoe, P. \& Webster, J. (1985) In vitro fertilization: a treatment for male infertility. Fert. Steril. 43, 422-432.

Corson, S.L., Bartzer, F., Eisenberg, E., English, M.E., White, S.M., Laberge, Y. \& Po, J.K. (1986) Early experience with the GIFT procedure. J. Reprod. Med. 31, 219-224.

Diamond, M.P., Rogers, B.J., Vaughan, W.K. \& Wentz, A.D. (1985) Effect of the number of insemination sperm and the follicular stimulation protocol of in vitro fertilization of human oocytes in male factor and non male factor couples. Fert. Steril. 44, 499-503.

Fraser, L.R. \& Drury, L.M. (1975) The relationship between sperm concentration and fertilization in vitro of mouse eggs. Biol. Reprod. 13, 513-518.

Fukoda, Y. \& Chang, M.C. (1978) Relationship between sperm concentration and polyspermy in intact and zona-free mouse eggs inseminated in vitro. Archs Androl. 1, 267-273.

Gordon, J.W. \& Talanski, B.E. (1986) Assisted fertilization by zona drilling: a mouse model for correction of oligospermia. J. exp. Zool. 239, 347-354.

Kerin, J.F.P., Peek, J., Warnes, G.M., Kirby, C., Jeffrey, R., Matthews, C.D. \& Cox, L. (1984) Improved conception rate after intrauterine insemination of washed spermatozoa from men with poor quality semen. Lancet, 1, 533.
Lassalle, B., Courtot, A.M. \& Testart, J. (1987) In vitro fertilization of hamster and human oocytes by microinjection of human sperm. Gamete Res. 16, 69-78.

Markert, C.L. (1983) Fertilization of mammalian eggs by sperm injection. J. exp. Zool. 228, 195-201.

Metka, M., Maromy, T. \& Hubert, J. (1985) Micromanipulatory sperm injection, a new method in the treatment of infertile males. Wien. Med.Wschr. 135, 55-59.

Modlinski, J.A. (1970) The role of the zona pellucida in the development of mouse eggs in vivo. J. Embryol. exp. Morph. 23, 539-547.

Quinn, P. \& Whittingham, D.G. (1982) Effect of fatty acids on fertilization and development of mouse embryos in vitro. $J$. Androl. 3, 440-444.

Quinn, P., Kerin, J.F. \& Warnes, G.M. (1985) Improved pregnancy rate in human in vitro fertilization with the use of a medium based on the composition of human tubal fluid. Fert. Steril. 44, 493-498.

Stanger, J.D. \& Quinn, P. (1982) Fertilization of cumulus-free, zona intact mouse ova in vitro at high and low sperm concentrations. Gamete Res. 5, 61-70.

Thadani, V.M. (1982) Mice produced from eggs fertilized in vitro at very low sperm-egg ratio. J. exp. Zool. 219, $277-283$

Tsunoda, Y. \& McLaren, A. (1983) Effect of various procedures on the viability of mouse embryos containing half the number of blastomeres. J. Reprod. Fert. 69, 315-322.

Tsunoda, Y., Yasiu, T., Nakamura, K., Uchida, T. \& Sugie, T. (1986) Effect of cutting the zona pellucida on the pronuclear transplantation in the mouse. $J$. exp. Zool. 240, I19-125.

Uehara, T. \& Yanagimachi, R. (1976) Micro surgical injection of spermatozoa into hamster eggs with subsequent transformation of sperm nuclei into male pronuclei. Biol. Reprod. 15, 467-470.

Yovich, J.L. \& Stanger, J.D. (1984) The limitations of in vitro fertilization from males with severe oligospermia and abnormal sperm morphology. J. In Vitro Fert. Embryo Transfer 1, 172-179.

Received 12 January 1988 